\title{
REDESAIN TEMPAT TIDUR UNTUK BALITA
}

\author{
Lidya Ekayana Saputri \\ Mahasiswa Program Studi Desain Produk, Jurusan Desain \\ Institut Teknologi Adhi Tama Surabaya \\ e-mail: lidyayana.le@gmail.com \\ Hamdan Bahalwan \\ Staf Pengajar Studi Desain Produk, Jurusan Desain \\ Institut Teknologi Adhi Tama Surabaya \\ e-mail : hamdan.despro@itats.ac.id
}

\begin{abstract}
Abstrak
Tidur merupakan suatu kondisi istirahat alami yang dialami oleh manusia dan hewan-hewan lainnya, yang sangat penting untuk kesehatan. Di Indonesia, orang tua dan bayi sejak lahir tidur satu ranjang (bed sharing), menyebabkan sindrom kematian mendadak pada bayi atau SIDS (Sudden Infant Death Syndrom). Alasan dari kebiasaan (bed sharing) adalah permasalahan harga produk yang mahal dan waktu penggunaan yang sebentar. Dengan permasalahan diatas, maka dibutuhkan redesain tempat tidur dengan waktu pengunaan yang panjang dan mengikuti perkembangan usia. Metode yang digunakan dalam pencariaan data adalah mix metode, yaitu metode penelitian menggunakan pendekatan kualitatif (metode penelitian dengan observasi dan wawancara) dan kuantitatif (metode penelitian berdasarkan hasil kuisioner yang menjadi data pendukung untuk penelitian). Tahap analisis meliputi analisis kebutuhan, analisis dimensi produk, analisis ergonomi, analisis material, analisis sistem, analisis bentuk, analisis warna, analisis finishing, analisis pertumbuhan anak. Kemudian didapatkan hasil,dari analisi tersebut berupa rekomendasi tiga desain alternatif.
\end{abstract}

Kata kunci : Redesain, SIDS, Tidur.

\begin{abstract}
Sleep is a natural resting condition experienced by humans and other animals, which is very important for health. In Indonesia, parents and infants from birth to one bed sharing, causing a sudden death syndrome in infants or a Sudden Infant Death Syndrom (SIDS). The reason for a habit (bed sharing) is the problem of expensive product prices and a short time of use. With the above problem, it is necessary to redesign the bed with long use time and follow the age development. The method used in data search is the mix method, which is the method of research using qualitative approach (research method with observation and interview) and quantitative (research method based on the results of the questionnaire that becomes data Support for research). Stage analysis includes needs analysis, Product dimension analysis, ergonomics analysis, material analysis, system analysis, form analysis, color analysis, finishing analysis, child growth analysis. Then obtained results, from the analysis in the form of recommendation three alternative designs.
\end{abstract}

Keywords: redesign, SIDS, sleep. 
Vol. 7, No. 2, April 2020

\section{Pendahuluan}

Tidur merupakan suatu kondisi istirahat alami yang dialami oleh manusia dan hewan-hewan lainnya, yang sangat penting untuk kesehatan. Setiap manusia membutuhkan waktu tidur kurang lebih sekitar sepertiga waktu hidupnya. Tentu saja hal ini masuk akal mengingat setiap harinya kita butuh waktu tidur beberapa jam untuk kembali memulihkan stamina tubuh. Secara alami dan otomatis jika tubuh lelah maka akan merasa mengantuk sehingga memaksa tubuh kita untuk beristirahat secara fisik dan mental.

Menurut alodokter.com, orang dewasa membutuhkan untuk tidur selama 7 - 8 jam sehari. Sedangkan bayi membutuhkan jam tidur yang jauh lebih panjang durasinya dibanding orang dewasa, bayi yang baru lahir membutuhkan waktu 16,5 jam sehari untuk tidur. Kebutuhan durasi tidur ini, lama - kelamaan akan berkurang seiring dengan bertambahnya usia seseorang.

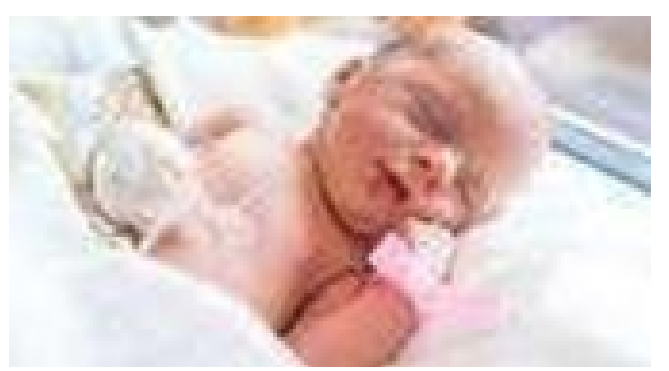

Gambar 1. Bayi baru lahir.

Sumber : https://bit.ly/2oIB1HR, 14 Oktober 2019. Pukul 21.00 WIB

Jika kebutuhan istirahat atau tidur manusia terpenuhi dengan baik, maka proses pertumbuhan manusia juga akan optimal. Sebaliknya, jika pola tidur atau istirahat terganggu pasti proses tumbuh kembangnya akan terganggu juga. Banyak hal yang disebabkan karena pola tidur yang terganggu mengakibatkan gangguan kesehatan, gangguan berpikir dan menurunnya $\mathrm{ke} \mathrm{ma} \mathrm{m-}$ puan berkonsetrasi. Oleh karena itu betapa pentingnya kualitas istirahat bagi seseorang bahkan sejak baru lahir.
Ada banyak pendapat dan teori mengenai menciptakan kondisi tidur yang ideal bagi bayi, teori ini berbeda - beda di setiap negara. Di Indonesia, banyak bayi yang baru lahir tidur satu ranjang dengan orang tuanya (bed sharing). Hal ini dikarenakan kebiasaan yang sudah berlangsung sejak lama, tidur satu ranjang dengan orang tua dianggap lebih aman dan membuat orang tua merasa memiliki kedekatan dengan anaknya.

Namun hal ini ternyata tidak sepenuhnya benar, sebab banyak studi atau penelitian yang dilakukan mengenai bahaya tidur satu ranjang (bed sharing) memiliki banyak resiko yang terjadi. Menurut sebuah penelitian menunjukkan bahwa penyebab utama sindrom kematian mendadak pada bayi atau SIDS (Sudden Infant Death Syndrome) adalah bayi tidur bersama orang dewasa di tempat tidur yang sama. SIDS merupakan penyebab utama kematian pada bayi berusia 1-12 bulan. Seorang pakar SIDS mengatakan bahwa bayi yang tidur bersama orang dewasa memiliki risiko lebih tinggi untuk mengalami hambatan pada jalur pernapasannya, kepanasan, menghirup kembali hembusan udara yang dikeluarkan, serta kepalanya bisa tertutup. Kesemuanya itu merupakan faktor pemicu terjadinya SIDS.

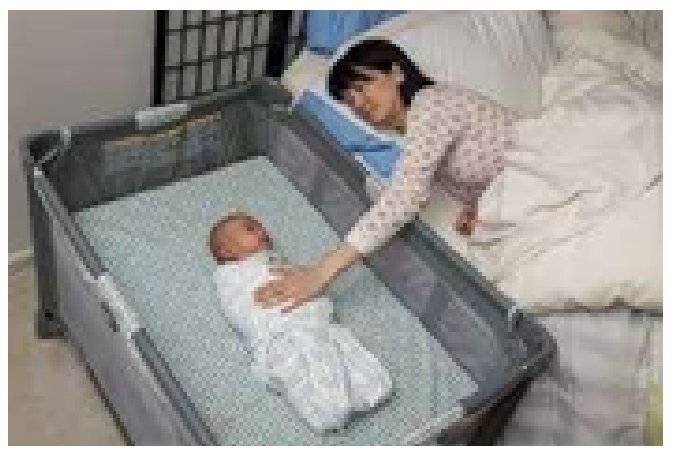

Gambar 2. Separate bed sleeping Sumber : https://bit.ly/2odTJXB, diakses pada 14 Oktober 2019, Pukul 21.10 WIB 
Lidya Ekayana Saputri, Hamdan Bahalwan, Redesain Tempat Tidur Untuk Balita

Karena budaya di Asia memang lebih banyak menerapkan bed sharing dibanding dengan menggunakan metode tidur terpisah dengan anak (separate bed sleeping) yang sudah diterapkan oleh banyak negara - negara maju seperti di Amerika, Australia, dan Eropa. Metode ini banyak digunakan karena para ahli di bidang kesehatan anak menganjurkan menggunakan metode separate bed sleeping.

Di Indonesia, separate bed sleeping belum banyak digunakan, sebab banyak orang tua merasa enggan dipisahkan dengan anaknya dikarenakan banyak alasan seperti keterbatasan tempat, takut mempengaruhi kedekatan antara orang tua dengan anaknya dan juga keterbatasan biaya. Banyak orang tua di Indonesia tidur terpisah dengan anak saat sudah berusia 3 tahun bahkan lebih. Padahal sebenarnya usia paling rawan resiko sindrom kematian mendadak pada bayi adalah usia anak 0 - 1 tahun.

Jumlah angka kelahiran di Indonesia meningkat dari tahun ke tahun. Berdasarakan data UNICEF yang diberitakan oleh ANTARA, pada tahun baru 2018 tercatat ada 386.000 bayi yang lahir. 90 persen bayi yang lahir tersebut dijelaskan berasal dari negara-negara berkembang. Sementara dari jumlah besar itu, Indonesia secara global menyumbang 13.370 kelahiran bayi. Jumlah tersebut menempatkan Indonesia di peringkat kelima dunia terbesar.

Peringkat pertama ditempati oleh India dengan angka kelahiran mencapai 69.070 disusul oleh Tiongkok di peringkat kedua dengan jumlah 44.760 bayi. Sementara di posisi ketiga ditempati oleh Nigeria yang mendapatkan 20.210 kelahiran bayi dan posisi keempat ditempati Pakistan yang meraih 14.910 bayi baru di tahun baru 2018 .

Mengingat pertumbuhan dan perkembangan bayi yang cukup cepat, penggunaan baby crib dapat dikategorikan memiliki usia guna yang cukup singkat. Banyak baby crib yang dijual dipasaran kebanyakan hanya dapat digunakan hingga usia maksimal 3 tahun. Sehingga barang tersebut nantinya akan berujung disimpan digudang atau beralih fungsi hanya menjadi tempat atau hanya menjadi bak penyimpanan mainan anak.

\section{Metode Perancangan}

Metode penelitian yang digunakan oleh peneliti dalam penelitiannya adalah metodemix method ialah penelitian kualitatif dan kuantitatif. Penelitian kualitatif bersifat deskriptif, peneliti menggunakan fakta sesuai di lapangan. Sedangkan penelitian kuantitatif menggunakan penghitungan secara sistematis menggunakan data kuisioner. Tujuan dari metode ini adalah me- Redesain Tempat Tidur Untuk Balita.

\subsection{Tahapan Penelitian}

Proses pengumpulan data dilakukan untuk memperoleh informasi yang dibutuhkan dalam rangka mencapai tujuan penelitian. Data yang dikumpulkan berupa :

\subsection{Identifikasi Masalah}

Pada tahap ini peneliti melihat permasalahan yang ada, kemudian melakukan penelitian untuk menyelesaikan permalasahan yang diteliti. Penelitian ini dilakukan kepada para konsumen pengguna tempat tidur balita.

\subsection{Pengumpulan Data}

Ada dua cara dalam pengumpulan data untuk pembuatan produk ini, yang pertama yaitu data primer dan data sekunder. Adapun penjelasannya sebagai berikut:

\subsubsection{Data Primer}

Pengumpulan data melalui pengambilan data faktual dilapangan meliputi kondisi yang ada. Mulai dari aktivtias hingga kebiasaan yang dilakukan balita dengan orangtua. Dan juga melakukan dokumentasi berupa foto untuk memudahkan peneliti saat mengamati dan agar menjadi pendukung laporan. 
Vol. 7, No. 2, April 2020

2.3.2 Observasi

Observasi dilakukan di tempat penjualan tempat tidur balita yaitu di Mothercare - Tunjungan Plaza Surabaya dan di Suzana baby shop - Jl. Ketajaya, Surabaya, dirumah yang menggunakan tempat tidur balita. Observasi juga dilakukan di Yayasan Cinta Kasih Ibu Teresa (Jl. Raya Bringin No. 5 Sambikerep, Surabaya) dan di Panti Asuhan Kasih Agape - Surabaya di Jl. Pakis Gg. 1 Surabaya

\subsubsection{Wawancara}

Wawancara merupakan cara untuk mendapatkan informasi tentang objek penelitian, yang diperoleh dari narasumber. Wawancara dilakukan oleh peneliti kepada :

1. Ibu Safa dan Ibu Erbithyang menggunakan tempat tidur untuk balitanya.

2. Pengurus balita di Yayasan Cinta Kasih Ibu Teresa (Jl. Raya Bringin No. 5 Sambikerep, Surabaya). Pengurus di Panti Asuhan Kasih Agape - Surabaya di Jl. Pakis Gg. 1, Surabaya

\subsubsection{Dokumentasi}

Dokumentasi digunakan untuk data, serta melaporkan hasil observasi yang telah dilakukan.

\subsubsection{Data Sekunder}

Pengambilan data sekunder yang dilakukan peneliti berguna untuk mendukung peneliti dalam proses pengumpulan data.

\subsubsection{Data Literatur}

Data literatur didapatkan peneliti dari media elektronik yaitu seperti e-book maupun jurnal. Data tersebut digunakan untuk menunjang penelitian yang dilakukan.

\subsubsection{Media Online}

Media online digunakan untuk mencari data tambahan, seperti referensi tentang informasi yang berkaitan dengan penelitian melalui internet.

\subsection{Pengumpulan data}

Setelah data sekunder, dan juga data primer dikumpulkan, sebagai acuan atau refrensi peneliti melakukan proses penelitian.

\subsection{Analisis}

Analisis data bertujuan untuk mendapatkan kesimpulan dari semua data yang telah diperoleh selama proses penelitian di lapangan.

\subsection{Sintesa Desain}

Sintesa desain merupakan hasil dari proses penelitian yang kemudian dianalisis, oleh peneliti kelebihan dan kekurangan dari hasil peneliti yang sudah dilakukan. Dari hasil analisis tersebut dapat diketahui, produk seperti apa yang akan diproduksi.

\subsection{Desain Alternatif}

Tahap selanjutnya adalah desain alternatif, pada tahap ini peneliti membuat alternatif sketsa produk.

\subsection{Pengembangan desain}

Tahap selanjutnya adalah pengembangan desain, pada tahap ini peneliti membuat pengembangan desain dari desain alternative terpilih.

\subsection{Final Desain}

Final desain merupakan desain terpilih dari beberapa alternatif desain, yang nantinya akan dijadikan sebuah produk.

\subsection{Produk}

Pada tahap ini adalah tahap pembuatan model produk yang akan di produksi, dengan acuan gambar teknik dan final desain.

\section{Pembahasan \\ 3.1 Studi kasus}

Studi kasus dilakukan dengan cara observasi, yang dilakukan di enam tempat berbeda. Yaitu dua panti asuhan yang ada di Surabaya, dua rumah responden yang memiliki balita dan menggunakan tempat 
Lidya Ekayana Saputri, Hamdan Bahalwan, Redesain Tempat Tidur Untuk Balita

tidur untuk balita, serta dua babyshop yang ada di Surabaya. Karena dalam penelitian ini membutuhkan infomasi mengenai tempat tidur untuk balita, dan dilakukan juga wawancara untuk mengetahui alasan responden menggunakan tempat tidur tersebut.

\subsection{Analisis ergonomi}

Analisis ergonomi dilakukan untuk mengetahui standart ergonomi pada tempat tidur balita, dengan acuan studi literatur dan hasil wawancara dengan responden. Berikut ini hal - hal yang menyangkut mengenai ergonomi produk tempat tidur untuk balita :

\section{Keamanan tempat tidur balita}

Banyak aspek yang menjadi pertimbangan dalam menentukan keaman pada tempat tidur baalita, diantaranya :

a. Kasur harus terpasang dengan baik, tidak boleh ada jarak lebih dari 2 jari antara kasur dan sisi tempat tidur.

b. Pagar pengaman berbentuk jeruji berjarak tidak lebih dari $6 \mathrm{~cm}$, agar tubuh balita tidak terhimpit diantara celah.

c. Pagar pengaman tidak diperbolehkan menggunakan sistem sliding yang dapat dinaik turunkan.

d. headboard / footboard tidak boleh menggunakan potongan dekoratif

e. bahan material harus solid dan halus.

f. Tidak boleh terdapat gantungan diatas kepala balita / mainan yang menggantung diatasnya.

g. Menempatkan tempat tidur jauh dari jendela, kabel, dekorasi dinding dan perabot yang bisa dipanjat oleh balita.

h. Permukaan tidur harus rata.

\section{Batas suara yang aman bagi telinga balita}

Tiap makhluk hidup memiliki batas ambang pendengaran, manusia memiliki batas ambang pendengaran pada frekuensi $20 \mathrm{~Hz}-20 \mathrm{kHz}$. Jika melampaui batas ambang pendengaran, maka akan menimbulkan kebisingan hingga kerusakan sistem pendengaran. Balita rentan terhadap kerusakan pendengaran akibat suara bising, karena tulang tengkorak yang masih tipis dan saluran telinga yang jauh lebih kecil dari orang dewasa. Balita menggunakan telinga untuk mengambil sejumlah besar informasi tentang dunia sekitar. Pendengaran juga membantu untuk belajar bahasa dan menstimulasi perkembangan otak. Telinga bagian dalam kan berkembang sepenuhnya sekitar 20 minggu pada masa kehamilan dan pada saat bayi baru lahir pendengarannya sudah berfungsi. Sehingga sejak baru lahir akan dapat mendengar dengan jelas. Batas besarnya suara yang aman bagi pendengar balita adalah tidak lebih besar dari 80 desibel (dB).

\subsection{Analisis Material}

Analisis ini dilakukan untuk mengetahui material yang diaplikasikan pada redesain tempat tidur untuk balita, dengan acuan studi literatur dan hasil wawancara dengan responden. Berdasarkan hasil analisis yang telah dilakukan peneliti, material utama yang digunakan pada redesain tempat tidur untuk balita yaitu material kayu lapis/plywood karena material tersebut paling banyak memenuhi kriteria dari kebutuhan redesain tempat tidur untuk balita.

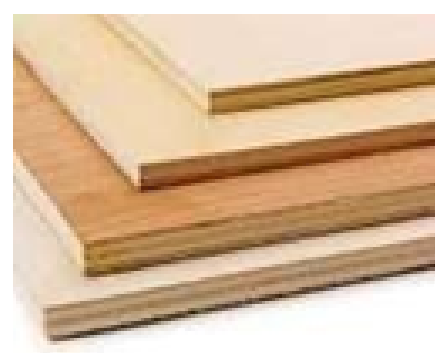

Gambar 3. Material Plywood/Multiplek Sumber : https://bit.ly/2W2pHT4, 14 Oktober 2019. Pukul 21.00 
Vol. 7, No. 2, April 2020

Kemudian untuk material pendukung pada tumpuan dan kerangka pada bagian alas menggunakan material besi

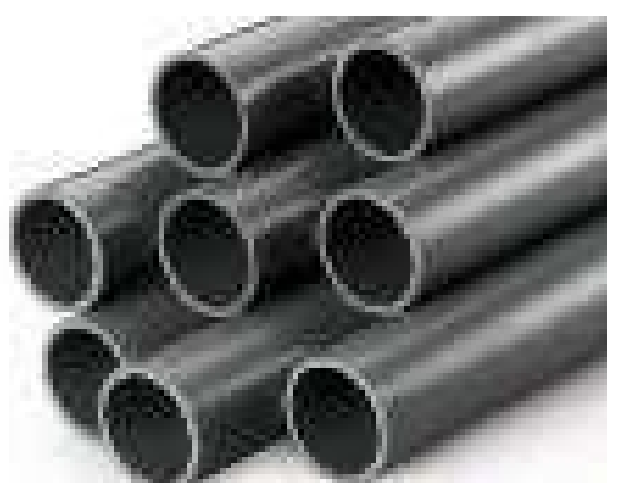

Gambar 4. Material besi

Sumber : https://bit.ly/2W6qxP0, diakses pada 14 Oktober 2019. Pukul 21.00

\subsection{Analisis Sistem}

Analisis ini dilakukan untuk mengetahui sistem yang sesuai untuk diaplikasikan pada redesain tempat tidur untuk balita. Dengan acuan studi literatur. Berdasarkan hasil analisis yang telah dilakukan peneliti, sistem yang sesuai untuk redesain tempat tidur balita.adalah :

1. Sistem sliding karena dapat membuat tempat tidur balita. menjadi lebih ringkas dan dapat dilipat atau diubah - ubah karena sifat sistem yang fleksible.

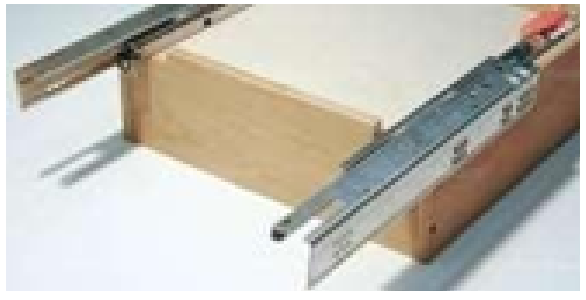

Gambar 5. Rel Laci Sliding Model Bawah (Tandem)

Sumber : https://bit.ly/343dPTV, diakses pada 18 Oktober 2019, Pukul 21.20
2. Untuk penyimpanan mainan balita, menggunakan laci dengan sistem engsel.

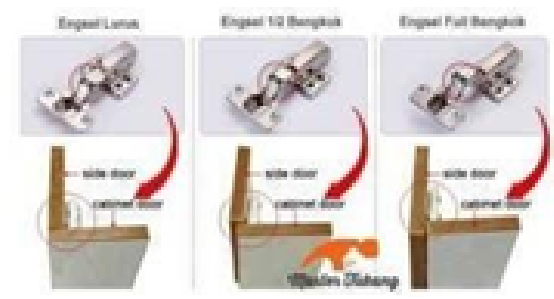

Gambar 6. Engsel Sendok

Sumber : https://bit.ly/2Nb5tTm, diakses pada 18 Oktober 2019, Pukul 21.15

3. Untuk pagar pengaman menggunakan sistem knock down, karena kuat dan bisa dilepas pasang.
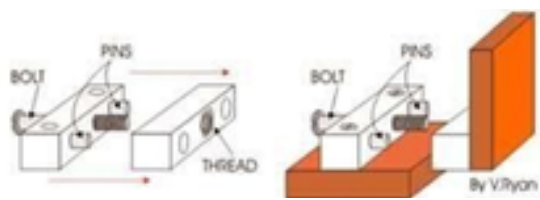

Gambar 7. Baut Knock Down: Two block fitting

Sumber : https://bit.ly/31Ism5G, diakses pada 18 Oktober 2019, Pukul 21.25

4. Untuk kebutuhan audio menggunakan speaker sub woofer karena jenis ini yang sesuai dan tidak membuat pendengaran pada balita terganggu

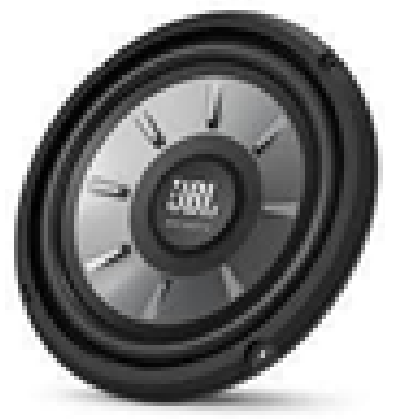

Gambar 8. Subwoofer

Sumber : shorturl.at/ayJP5, diakses pada 18 Oktober 2019, Pukul 21.35 
Lidya Ekayana Saputri, Hamdan Bahalwan, Redesain Tempat Tidur Untuk Balita

\section{5 Analisis Bentuk}

Analisis ini dilakukan untuk mengetahui bentuk yang akan diaplikasikan pada redesain tempat tidur untuk balita. Berdasarkan hasil observasi yang telah dilakukan. Berikut adalah kebutuhan bentuk yang ditujukan untuk redesain tempat tidur balita adalah :

1. Fleksible

2. Ruang gerak yang cukup luas

3. Aman bagi balita

Peneliti memilih bentuk persegi panjang adalah bentuk yang sesuai dengan kebutuhan produk yang akan dibuat oleh peneliti, ialah produk yang dapat diubah dimensi produknya sesuaidengan pembagian usia. Sehingga diperlukan bentuk yang dapat mudah dipanjang - pendekkan
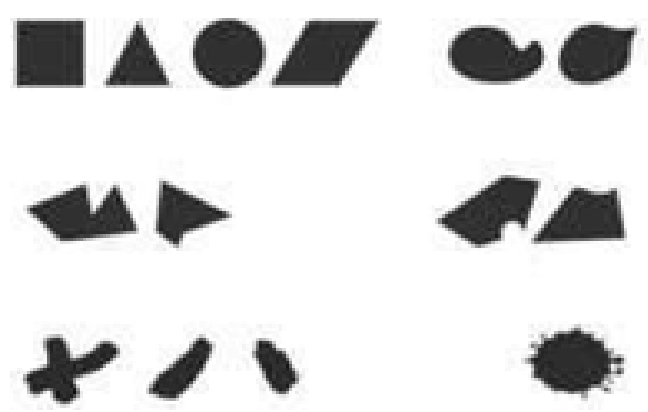

Gambar 9. Bentuk berupa bidang

Sumber : Dasar Desain Dwimatra (Said,2006:17-19), diakses pada 18 Oktober 2019, pukul 21.30
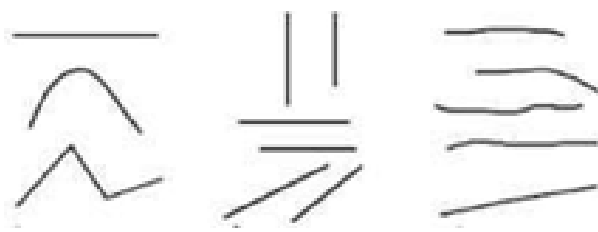

Gambar 10. Bentuk berupa garis

Sumber : Dasar Desain Dwimatra (Said,2006:17-19), diakses pada 18 Oktober 2019, Pukul 21.30 WIB

\subsection{Analisis Warna}

Analisis ini dilakukan untuk mengetahui warna yang diaplikasikan pada redesain tempat tidur balita, dengan acuan studi literatur dan hasil wawancara yang dilakukan sewaktu observasi. didapatkan warna putih yang menjadi warna dominan yang akan diaplikasikan pada redesain tempat tidur untuk balita karena warna tersebut memenuhi keseluruhan kebutuhan produk yang akan dibuat

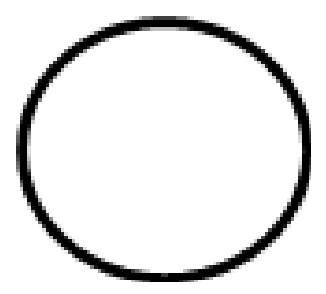

Gambar 11. Warna putih

Sumber : dokumentasi pribadi

Warna biru menjadi warna tambahan yang akan digunakan pada produk tempat tidur untuk balita $\mathrm{k}$ a re n a pengaruh dari warna tersebut yang berpengaruh pada emosi pengguna yaitu menimbulkan ketenangan.

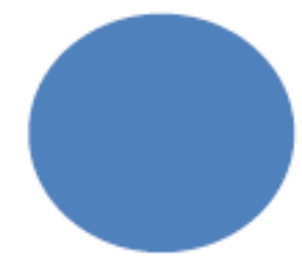

Gambar 12. Warna biru Sumber : dokumentasi pribadi

Peneliti juga memilih warna hitam untuk diaplikasikan pada bagian bawah tempat tidur balita karena sifatnya yang menggambarkan kekuatan dan kokoh. 
Vol. 7, No. 2, April 2020

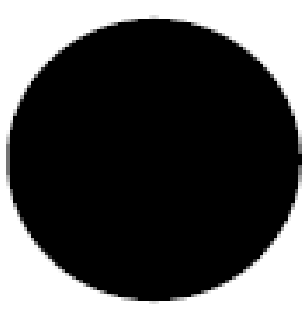

Gambar 13. Warna hitam Sumber : dokumentasi pribadi

\subsection{Analisis Finishing}

Analisis ini dilakukan untuk mengetahui finishing yang sesuai untuk diaplikasikan pada material tempat tidur untuk balita dengan acuan studi literatur dan hasil wawancara. Hasil analisis yang telah dilakukan peneliti, material finishing HPL yang digunakan pada redesain tempat tidur yang diaplikasikan pada lapisan dari material plywood

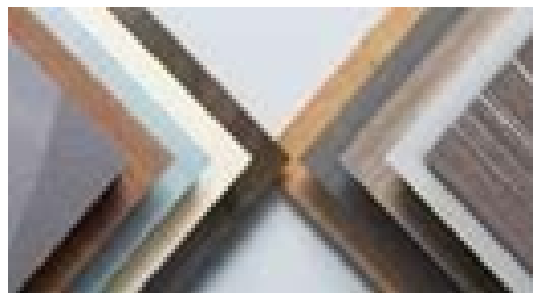

Gambar 14. Material HPL

Sumber : https://bit.ly/2W1ndod, diakses pada14 Oktober 2019. Pukul 21.0

Sedangkan pada bagian material besi menggunakan finishing epoxy karena tingkat ketahanan melawan karat yang sangat baik.

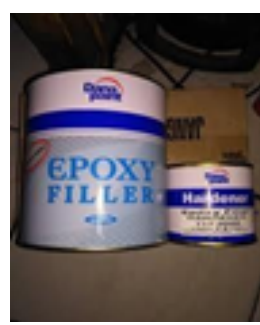

Gambar 15. Epoxy

Sumber : https://cutt.ly/ve3svEl, diakses pada 1 Desember 2019,

Pukul 20.00

\subsection{Analisis Pertumbuhan Anak}

Analisis ini dilakukan untuk mengetahui perkembangan anak balita mulai dari usia $0-5$ tahun berdasarkan data yang didapat dari penelitian terdahulu serta diyakinkan lagi melalui observasi yang sudah dilakukan. hasil analisis diatas, maka dapat diketahui kebutuhan apa saja yang diperlukan balita menurut perubahan usianya.

Berikut diantaranya :

a. $0-1,5$ bulan $=$ Memerlukan alas tidur yang nyaman karena aktivitasnya lebih banyak dihabikan untuk tidur. Juga diperlukan pagar pengaman untuk menjaga. Karena pada usia ini juga belum banyak aktifitas yang dilakukan diperlukan alat yang dapat membuat rasa tenang, yaitu berupa speaker yang berguna sebagai alat yang membuatnya merasa terjaga.

b. 1,5 -3 bulan $=$ Memerlukan ruang yang cukup lebar untuk dapat bergerak dan mainan yang dapat menstimulus motoriknya dan pagar pengaman agar tidak terjatuh.

c. $3-6$ bulan $=$ Memerlukan penjagaan yang lebih, diperlukan pagar pembatas agar tidak terjatuh dan mainan untuk merangsang kerja motorik balita. Serta diperlukan speaker untuk mendengarkan lagu yang dapat menambah keceriaan saat bermain.

d. $6-9$ bulan = Diperlukan pagar pengaman yang kuat karena balita mulai bergerak aktif dan belajar untuk berdiri dan tahap belajar berjalan.

e. $9-12$ bulan = perlukan pagar pengaman yang kuat karena balita sudah sangat aktif.

f. 1 - 2 tahun = Diperlukan pagar pengaman yang kuat karena balita sudah belajar untuk berdiri. Mainan untuk mengasah kemampuannya.

g. 2 - 3 tahun = Diperlukan pagar pengaman yang kuat karena balita dan mainan yang sesuai dengan usianya.

h. $3-5$ tahun $=$ Tinggi tempat tidur bisa lebih dipendekkan sebab balita sudah 
Lidya Ekayana Saputri, Hamdan Bahalwan, Redesain Tempat Tidur Untuk Balita

lebihj mandiri namun tetap di berikan pagar pengaman.

\subsection{Sintesa Desain}

Sintesa desain merupakan hasil dari keseluruhan analisis kebutuhan desain.

Berikut spesifikasi produk redesain tempat tidur untuk balita:

a. Pembagian usia sesuai pada pembagian antropometri tinggi badan balita. yang menghasilkan dimensi produk sebagai berikut sesuai pembagian usianya : Dimensi produk untuk usia $0-6$ bulan Panjang $=60 \mathrm{~cm}$, Lebar $=75 \mathrm{~cm}$, Tinggi $=98 \mathrm{~cm}$.

Dimensi produk untuk usia 6 bulan -2 tahun Panjang $=120 \mathrm{~cm}$ Lebar $=75 \mathrm{~cm}$ Tinggi $=98 \mathrm{~cm}$ Dimensi produk untuk usia 2 tahun -5 tahun Panjang $=120$ $\mathrm{cm}$ Lebar $=75 \mathrm{~cm}$ Tinggi $=98 \mathrm{~cm}$

b. Material utama yang digunakan pada redesain tempat tidur untuk balita yaitu material kayu lapis/plywood. Kemudian untuk material pendukung pada tumpuan dan kerangka pada bagian alas menggunakan material besi.

c. Sistem yang digunakan pada produk redesain tempat tidur untuk balita adalah : 1) Sistem sliding pada bagian alas tidur, 2) Sistem engsel. Untuk penyimpanan mainan balita, 3) Sistem knock down pada pagar pengaman, 4) Speaker sub woofer sebagai audio

d. Bentuk yang akan diaplikasikan pada redesain tempat tidur untuk balita adalah bentuk geometris dengan kombinasi lengkungan agar aman bagi balita. Bentuk geometris yang dipilih adalah bentuk persegi panjang.

e. Warna yang diaplikasikan pada produk dominan warna putih dengan tambahan warna biru pada bagian tempat tidur, sementara pada bagian alas digunakan warna hitam.

f. Finishing produk menggunakan HPL untuk melapisi plywood dan epoxy sebagai pelapis dari material besi.

\subsection{Konsep Desain}

Konsep desain yang diaplikasikan pada produk redesain tempat tidur untuk balita adalah comfortable and clean. Comfortable dalam Bahasa Indonesia memiliki arti nyaman, menyenangkan dan nyenyak, yang berkaitan dengan fungsi produk yang akan dibuat yaitu tempat tidur. Kemudian clean yang dimaksud, berhubungan dengan warna yang digunakan yaitu dominan warna putih yang menggambarkan kebersihan / higienis.

\subsection{Alternatif desain Alternatif desain 1}

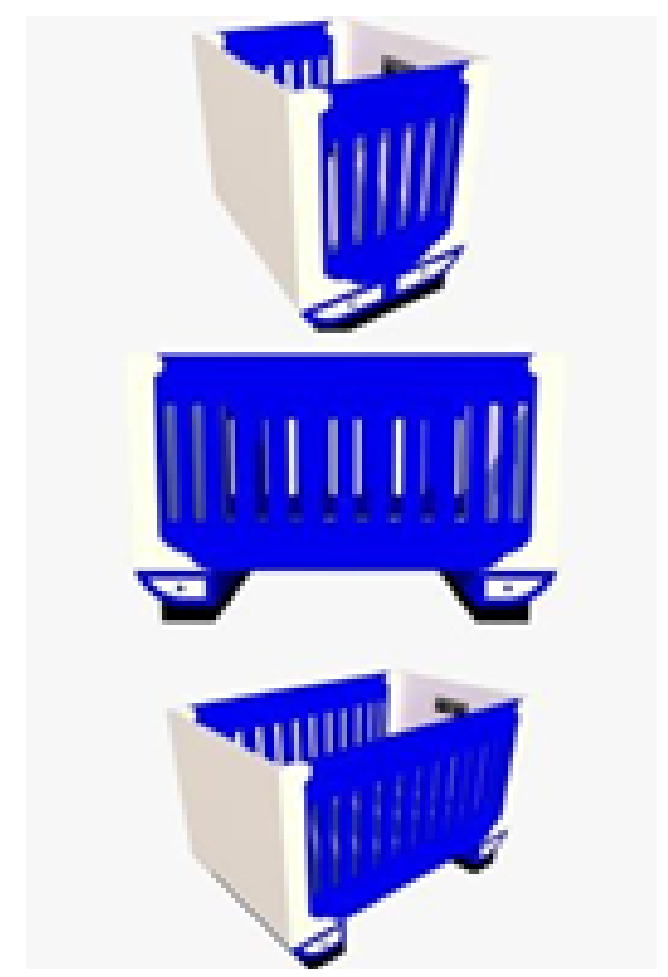

Gambar 16. Alternatif Desain 1 
Vol. 7, No. 2, April 2020

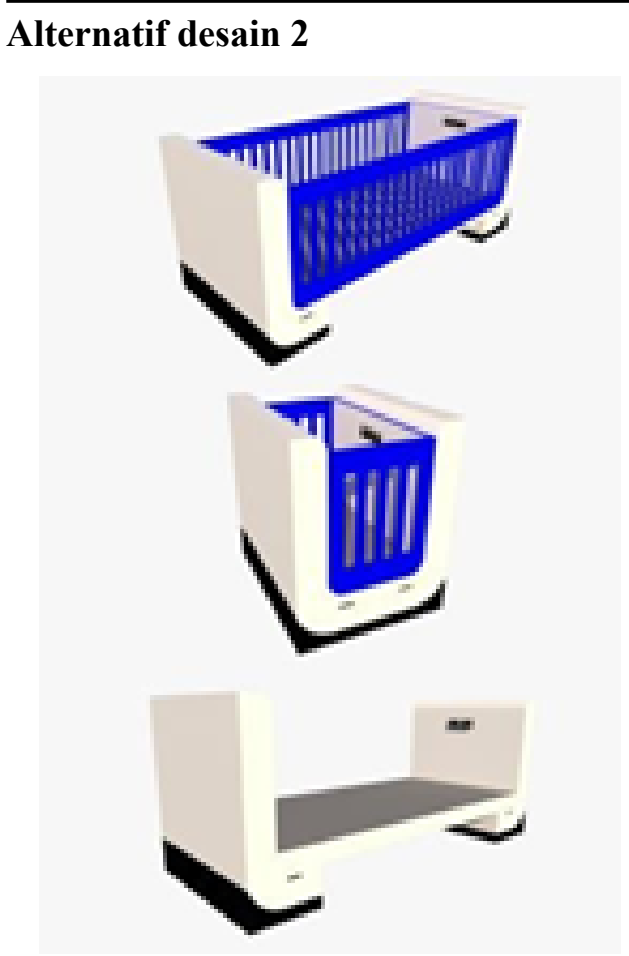

IV. Kesimpulan

Berdasarkan tahapan penelitian yang telah dilakukan terhadap redesain tempat tidur untuk balita, dapat ditarik kesimpulan bahwa tempat tidur untuk balita yang ada di pasaran selama ini kurang memenuhi keperluan dari perkembangan balita. Dengan harga yang cukup mahal dan dengan waktu penggunaan yang sebentar. Sehingga redesain tempat tidur untuk balita yang akan dibuat ini diharapkan dapat menjadi solusi yang tepat dan bermanfaat

Gambar 17. Alternatif Desain 2

\section{Alternatif desain 3}

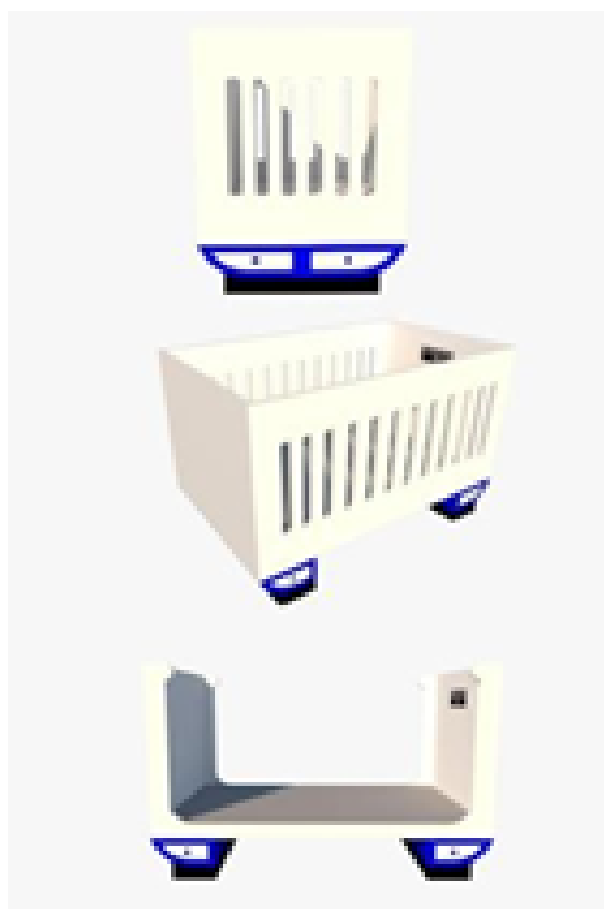

Gambar 18. Alternatif Desain 3 
Lidya Ekayana Saputri, Hamdan Bahalwan, Redesain Tempat Tidur Untuk Balita

\section{DAFTAR PUSTAKA}

Maxmanroe. 2020. Pengertian Desain: Fungsi, Tujuan, Prinsip, dan Jenis Desain. https:// www.maxmanroe.com/vid/umum/pengertian-desain.html.(13 Oktober 2019)

Bertaria Alvionita, Adi Santosa, dan Anik Rakhmawati. 2016. Perancangan Compact Furnitur untuk Penghuni Rumah Susun di Surabaya. JURNAL INTRA Vol. 4, No. 2, 195-202

Said, Abdul Aziz. 2006. Dasar Desain Dwimatra. Makasar. UNM Makasar Nopsa, Angga. 2017. Tugas Akhir Desain Convertible Baby Crib Dengan Konsep Mempererat Hubungan Antara Ibu Dan Anak. Surabaya. Institut Teknologi Sepuluh November

American Academy of Pediatrics. 2019. Adapted from Caring for Your Baby and Young Child : Birth to Age 5. Jurnal 6th Edition

Ardini, Sarihati. 2017. Pengaruh Warna Pada Elemen Interior Ruang Tunggu Rumah Sakit Ibu Dan Anak Terhadap Psikologis Pengunjung, Studi Kasus Rumah Sakit Ibu Dan Anak Melinda Bandung. Jurnal Idealog Vol.2 No.3

Megan, dkk. 2019. Effect of Education and Cardboard Bassinet Distribution on Newborn Bed-Sharing. Jurnal Vol. 6

Bertaria Alvionita, Adi Santosa, Anik Rakhmawati. 2016. Perancangan Compact Furnitur untuk Penghuni Rumah Susun di Surabaya. Jurnal Vol 4, No 2

Kementrian Kesehatan RI. 2016. Buku Kesehatan Ibu Dan Anak. Jakarta. Kementrian Kesehatan dan JICA

Bahalwan, Hamdan. 2018. Kajian Psikologis Desain, Desain Interface Speedometer Sepeda Motor Metik, Tentang Pengaruh Cara Orang Berkendara. Jurnal IPTEK Vol. 22, No. 2 